\title{
Energy-Efficient Hybrid Power System Model Based on Solar and Wind Energy for Integrated Grids
}

\author{
Nishant Jha $\mathbb{D}^{1},{ }^{1}$ Deepak Prashar $\left(\mathbb{D},{ }^{1}\right.$ Mamoon Rashid $\mathbb{D}^{\circ},{ }^{2}$ Zeba Khanam, ${ }^{3}$ \\ Amandeep Nagpal, ${ }^{1}$ Ahmed Saeed AlGhamdi $\mathbb{D}^{4},{ }^{4}$ and Sultan S. Alshamrani $\mathbb{D}^{5}$ \\ ${ }^{1}$ School of Computer Science and Engineering, Lovely Professional University, Jalandhar 144411, India \\ ${ }^{2}$ Department of Computer Engineering, Faculty of Science and Technology, Vishwakarma University, Pune 411048, India \\ ${ }^{3}$ College of Computing and Informatics, Saudi Electronic University, Dammam, Saudi Arabia \\ ${ }^{4}$ Department of Computer Engineering, College of Computer and Information Technology, Taif University, P.O. Box 11099, \\ Taif 21994, Saudi Arabia \\ ${ }^{5}$ Department of Information Technology, College of Computer and Information Technology, Taif University, P.O. Box 11099, \\ Taif 21944, Saudi Arabia
}

Correspondence should be addressed to Mamoon Rashid; mamoon873@gmail.com

Received 10 October 2021; Revised 15 January 2022; Accepted 26 January 2022; Published 21 February 2022

Academic Editor: Araz Darba

Copyright (c) 2022 Nishant Jha et al. This is an open access article distributed under the Creative Commons Attribution License, which permits unrestricted use, distribution, and reproduction in any medium, provided the original work is properly cited.

Global energy needs have risen in recent years, and traditional energy sources such as fossil fuels are no longer viable. To meet the growing electricity demand, attention has moved to renewable energy sources such as solar and wind energy. Furthermore, the development of clean energy is vital for combating climate change. Various studies have shown the effectiveness of using hybrid systems (combination of solar photovoltaic and wind energy systems) for generating power. However, a significant amount of energy gets wasted. To prevent the wastage of energy, a dual-energy generation system for integrated grids has been suggested in this paper. The load data have been collected from various regions in Rajasthan, India. An optimal grid system configuration is designed using net present cost and cost per unit of energy. Other factors such as the tilt angle of PV array optimization, wind energy, and inverter optimization have also been used for increasing the reliability and stability of the system. Sensitivity analysis has been performed to analyze the effective variations of the capital costs on the developed system economy. The results obtained from the simulations show that the overall costs of generating electricity from diesel systems and nongrid-based systems have been reduced to $20 \%$ at $10 \%$ annual capacity shortage allowance. Upon cost analysis, we found that the total cost for installing the suggested system is 49,500 USD, whereas for other systems, the costs came out as 66,000 USD, 56,500 USD, and 56,300 USD, respectively.

\section{Introduction}

Hybrid energy systems have received worldwide attention for remote locations where grid supply is not feasible [1]. In remote areas, various renewable energy technologies such as standalone solar systems and minigrids have been introduced to achieve an efficient energy supply [2]. However, many of them do not offer real versatility to the end user or are not practical when they are launched, usually due to the lack of sales to offset product replacement and operating and repair costs. Furthermore, in the light of global grid growth, the concern that grid arrival at a particular location will render off-grid systems useless has recently spread among energy system investors $[2,3]$. Climate change has become a major environmental concern in recent years as Green House Gas (GHG) emissions have increased [4]. As a result, it has been urged to look for alternative energy sources that can produce electricity [4], and wind and solar energy have been proven to be effective in producing cost-effective electricity [4]. In older times, only solar energy was used for generating electricity. Using only solar energy systems is having some challenges. These systems are not capable of 
generating maximum power during cloudy or rainy days [5]. People who use this system will be without power until the battery has been discharged [5]. Maximum power can be produced by combining solar and wind energy production techniques [5]. For electric power generation systems, these kinds of integrated systems guarantee a pollution-free and accident-free inventory [5]. Various off-grid methodologies, such as hydroenergy and geothermal energy, have been tried in the past few years to improve power supply reliability, but they have failed $[6,7]$. The key cause for such strategies' inability is their high energy prices, which are unaffordable on a broader scale $[6,7]$. The system presented in this paper is based on various optimization techniques for enhancing the efficiency of the system, which can provide continuous power at lower costs, thus reducing the financial pressure on people living in rural areas. Integrating solar and wind energy into hybrid power generation systems will minimize induced power volatility relative to single Variable Renewable Energy (VRE) systems, increasing overall system efficiency and reliability [7]. As a result, the amount of capacity used in the device can be decreased significantly, resulting in significant cost savings [7]. The major contributions of the paper are as follows:

(i) In this paper, a hybrid and effective system for harnessing power is suggested based on IoT and a combination of solar and wind energy

(ii) The aim of this paper is to find the solution to the challenges in resolving carbon emission and enhancing power efficiency, along with the focus on predicting the cost of energy from the system

The remainder of the paper is organized as follows. The associated work is covered in Section 2. The importance of the research is explained in Section 3. The proposed architecture and optimization methods are explained in Section 4. Section 5 summarizes the research findings, and Section 6 concludes the paper. Section 7 explains the limitation of the current study and future scope of work.

\section{Related Work}

Due to increased awareness regarding climate change and other environmental issues, the expectations for generating power from renewable sources of energy have increased [8]. Various studies have been conducted to suggest cost-effective and efficient systems for generating electricity. In [8], the authors have suggested a novel analysis technique for pumped storage and thermal power generator with a detailed introduction of renewable energy sources (RESs). For addressing operational planning for thermal power generators and output decisions for pumped storage, this paper uses Tabu search and interior point methods [9, 10]. The authors of [11] gave a high-level overview of the functional integration of hybrid renewable energy systems (HRES) in multienergy buildings. The paper discussed the most commonly used HRES solutions in the residential sector, as well as an investigation of HRES integration with thermal and electrical loads in residential apartments, which were then connected to external energy grids. The authors of [12] demonstrated the advantages of expanding the integration of renewable energy sources in the insular system. The main focus of this paper is on profit maximization, cost efficiency, GHG reduction, and time consumption in power generation. The authors of [13] submitted a review of different control strategies used by battery storage systems for smoothing the output power of wind turbines in order to improve future energy applications. The authors of [14] applied model predictive control to a three-phase inverter and used another model to estimate future system voltage forecasts for a given set of voltages. The method presented in this paper avoids the use of linear and nonlinear controllers by avoiding the use of a modulator, and it was found to be effective and simple to implement. The authors used an integrated approach in [15], combining spatially explicit resource potential analysis with high spatial resolution modeling of the US electricity system. Various wind supply curves, reflecting variations in siting regimes such as regulatory, physical, and social land-use factors, are analyzed in this study to determine the impact of potential wind growth. In [16], the authors have optimized a hybrid energy system for catamaran ship. The authors have discussed PV performance, generator performance, dual-input buck boost, and simulation. In [17], the authors have suggested an economic day-ahead scheduling technique for a sustainable cogeneration system. A dynamic programming model was developed for which the goal is to minimize fuel consumption. In [18], the authors have focused on the design and performance analysis of dual-axis tracking solar systems. The authors have also conducted a detailed review of various types of solar tracking systems and types of solar PV cells. The performance analysis for various solar PV systems suggested by other authors as per the literature reviewed is compared in Table 1. Recent development also focuses on developing efficient battery technology for energy storage in smart grid systems. In [26], the authors have developed a power management system, which is capable of controlling the power flow for an integrated system. However, using this technology as a storage system will make the overall system more expensive, which might not be affordable for lowincome countries. We want to keep the system as simple as possible through which we can cover both high-income and low-income countries. The authors of [27] have discussed finding an effective solution to replace natural gas for power generation with wind and solar energy. This study has also discussed the different cases of carbon-dioxide emission and the total cost of energy. However, the scope of the study is limited as in countries like Yemen and Saudi Arabia, natural gas is the most widely used for power generation, and it is not possible to extract the full potential of the integrated grid systems in these regions. So we have to develop a low-cost system to avoid wastage of investments in installing integrated systems under these conditions.

In [28], the authors have suggested a model for calculating tariffs at charging stations for electric vehicles. This paper also suggests the use of solar energy for charging electric vehicles (EVs). The approach suggested in this paper is unique, but various factors that affect the efficiency of the system such as tilt angle of the PV array have not been 
TABLE 1: Comparison between performances of various PV systems.

\begin{tabular}{|c|c|}
\hline Reference & Performance of the model suggested \\
\hline [19] & The peak power for the solar PV system was computed to be $1928 \mathrm{wp}$. \\
\hline [20] & The output efficiency of the PV system was largely affected by the rise in temperature. \\
\hline [21] & $\begin{array}{c}\text { The total energy generated from the system to fulfill the required load was } 26 \% \text { from grid, } 32 \% \text { from fuel cells, and } 42 \% \text { from } \\
\text { solar PV. }\end{array}$ \\
\hline [22] & $\begin{array}{c}\text { The energy costs for a standalone system with a reformer were computed to be } 0.164-0.233 \mathrm{USD} / \mathrm{kWh} \text {. The addition of fuel cells } \\
\text { to the hybrid systems will also increase these costs by } 33-37 \% \text {. }\end{array}$ \\
\hline [23] & annual power generated by the system suggested by the authors and del \\
\hline [24] & $\begin{array}{c}\text { Two hybrid power systems were suggested. Both the electrical efficiency and fuel economy have increased up to } 2 \% \text { and } 12 \% \text {, } \\
\text { respectively. }\end{array}$ \\
\hline [25] & $\begin{array}{c}\text { Emission of GHG for hybrid energy systems with supercapacitor energy storage systems decreases by } 814,428 \text { gallons of the } \\
\text { same diesel. }\end{array}$ \\
\hline
\end{tabular}

discussed. In [29], the authors have suggested a trigeneration system that produces ammonia, hydrogen, and electricity through the integrated solar system. This system can be fully implemented in high-income and middle-income countries, but in low-income countries, implementing this technique would be challenging as ammonia is a harmful substance and might cause respiratory diseases to the person who is operating the energy system or living nearby the system.

Upon analysis of the literature, we found that most of the works focus on developing complex systems which might affect the efficiency of the system and are not feasible for lowincome or poor nations. Through this paper, we have tried to improve the system through various optimization techniques so that the system would be feasible for all.

\section{Significance of Work}

In contrast to conventional fossil fuel-based resources, renewable energy sources play a critical role in maintaining the country's economy and quality of life [30]. Due to the increase in severe problems as a result of climate change, this research may be useful in addressing the issues to some extent. Using an integration of solar energy and wind energy will cause zero pollution, low greenhouse emissions, and fewer challenges related to waste management [31]. The system suggested in this paper is a better alternative for nuclear energy for fulfillment of $100 \%$ of electricity needs of the world [31]. The solution suggested in this paper will help in achieving a continuous power supply without the risk of harming nature or humans. Various studies have shown only a single renewable energy source for producing electricity, either solar energy or wind energy. Single renewable sources, on the other hand, become problematic in terms of operational costs and energy yield due to the intermittent nature of renewable sources [32]. Two or more renewable sources are combined to form a hybrid energy system (HES) based on these drawbacks [32]. The main aim of implementing such a system is to maximize power production, lower operating costs, and increase system productivity [32]. The hybrid system proposed in this paper can be quickly introduced to provide end users with highly efficient and reliable power. An HES may be used as a standalone system or as part of a grid [32]. Standalone systems, on the other hand, need a lot of storage to handle the load [32]. In grid- connected systems, the storage can be small, which can decrease the efficiency of the system. So, it is advised to use HES in standalone modes for generating high power. The energy produced from the suggested system is stable without causing any type of pollution. With the current challenge of not having enough space to construct power plants as the world's population grows, it is critical to make efficient use of land used to produce electricity and to think carefully when constructing a power plant. The power plant must be located near the power availability area to avoid power transmission losses and low power transit costs [31]. Thus to increase the reliability of power generation, integrated systems are used. Furthermore, to increase the dependency of the overall system only on one technique, either solar/wind energy, the size of the storage battery is needed to be reduced and using integrated systems would help in achieving this.

\section{System Architecture}

There has been an increase in demand for renewable energy sources as the prices of nonrenewable energy sources have risen [33]. As a result, this paper proposes that electricity is generated using hybrid systems based on solar and wind energy. The windmills start rotation and generate electricity with the help of magnetic coupling between a rotating magnetic coil and a stationary magnetic coil when enough wind is available at the area where the system is supposed to be installed. This technique harnesses both wind and solar energy [33]. The working of the system is shown in Figure 1.

The wind turbine generator is used to charge the battery in Figure 1, and the ATMega 328 Microcontroller is used for smart sensing and charging of the batteries, with the output displayed on the LCD screen. The solar panels mounted on the revolving plates ensure optimum daylight visibility for producing enough power for charging the batteries. This system is a good example of how the natural resources can be effectively used for producing electricity at cheaper rates [33]. The internal working of the system can be explained as follows. The photovoltaic (PV) subsystem consists of PV modules connected in series or parallel according to the requirements. Power is generated by ultraviolet (UV) rays from the sun. Direct Current (DC) is produced, and then it is converted to Alternating Current (AC) with the help of an inverter [34-36]. For maximizing the power generation, 


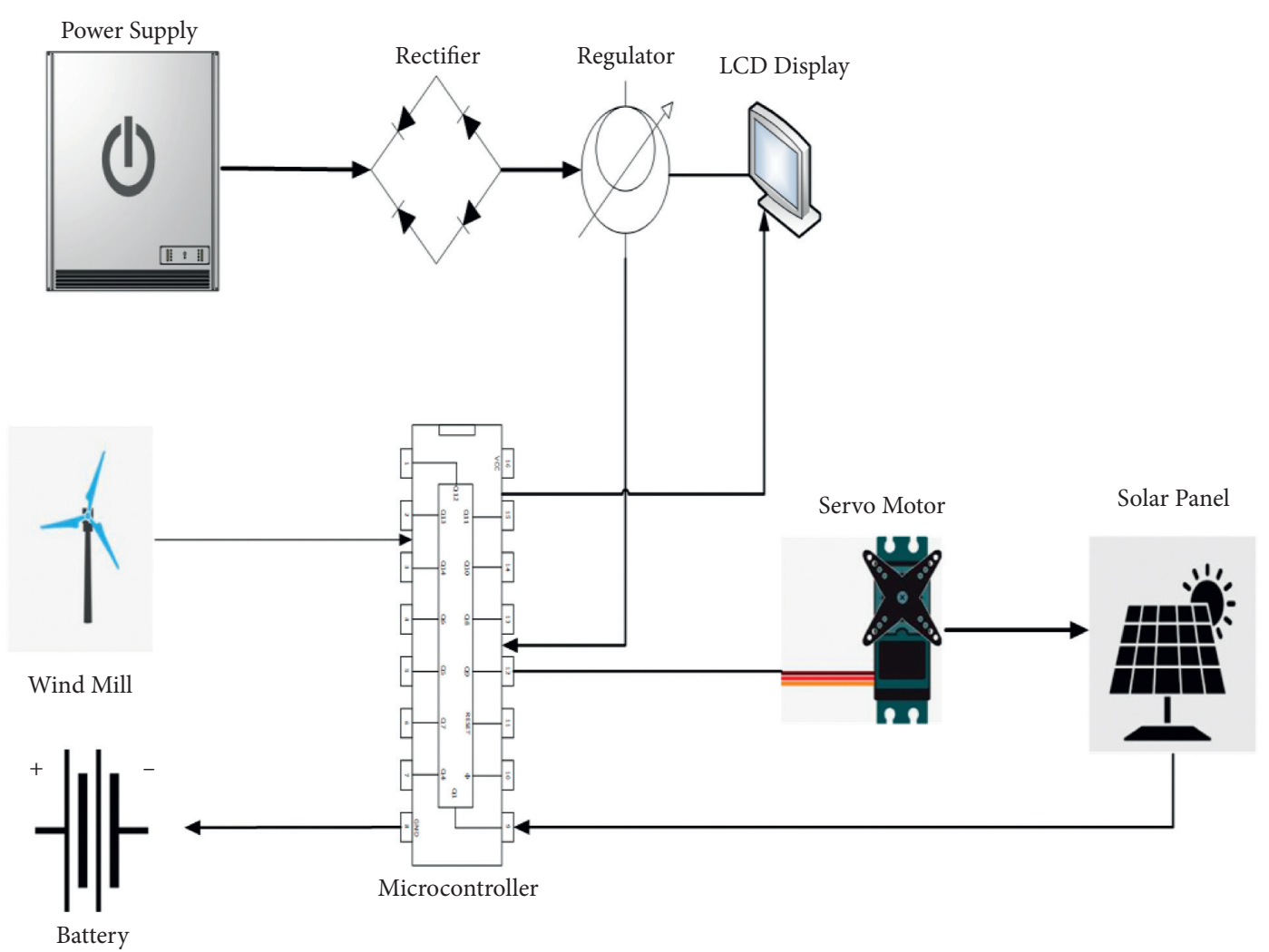

Figure 1: System working representation.

Maximum Power Point Technique (MPPT) [36] is used. The output power can be calculated as given in equations (1) to (7) $[37,38]$.

$$
\begin{aligned}
Z_{\mathrm{MPPT}}(t) & =J_{\mathrm{MPPT}}(t) * K_{\mathrm{MPPT}}(t) \\
J_{\mathrm{MPPT}}(t) & =J_{s}\left[1-\alpha\left(\exp \left\{\frac{K_{\max }}{\beta * K_{c}}\right\}\right)\right]+\Delta T(t), \\
K_{\mathrm{MPPT}}(t) & =K_{\max }+\phi J_{c} . \Delta T(t) \\
\alpha & =\left(1-\frac{J_{\max }}{J_{s}}\right) * \exp \left(-\frac{K_{\max }}{\beta * K_{c}}\right) \\
\beta & =\left(\frac{J_{\max }}{J_{c}}\right) *\left[\ln \left(1-\frac{J_{\max }}{J_{s}}\right)\right]^{-1}, \\
\Delta J(t) & =J_{s}\left(\frac{I R(t)}{R_{\mathrm{ref}}}-1\right)+\theta_{1, s} * \Delta T(t) \\
\Delta T(t) & =T_{x}-T_{x, \mathrm{ref}},
\end{aligned}
$$

where $J_{c}$ is the voltage of open circuit, $J_{\mathrm{s}}$ is the short-circuit current, $K_{\max }$ and $J_{\max }$ are the voltage and current at the maximum output power, $\theta_{1, s}$ is the temperature coefficient of power, $\operatorname{IR}(\mathrm{t})$ is the incident radiation on the PV surface, $T_{\mathrm{x}}(\mathrm{t})$ is the cell temperature that varies with ambient temperature and solar radiation, and $T_{\mathrm{x}, \mathrm{ref}}$ is the $\mathrm{PV}$ temperature under normal conditions. Control systems are used for maintaining an equilibrium between the power supply and load. When the power is generated in excess, then it is stored in the storage system and when the power demanded is in excess, then it provides the backup [34-36]. Charge controllers are also used for maintaining a balance between charging and discharging to enhance the life of batteries [36]. The charging and discharging of the batteries are given as $[37,38]$

$$
\begin{aligned}
& S_{f}=S(t-1) *(1-\sigma)+\left[X(t)-\frac{X J(t)}{\phi}\right] * \phi_{\text {charge }} \\
& S_{f}=S(t-1) *(1-\sigma)+\left[X(t)-\frac{X J(t)}{\phi}\right] * \phi_{\text {discharge }}
\end{aligned}
$$

where $S(t)$ and $S(t-1)$ are the charging and discharging states, $\sigma$ is the discharging speed of the battery for 1 hour, $X J(t)$ is the power of the load, $X(t)$ is the output power of the renewable sources, and $\phi_{\text {discharge }}, \phi$, and $\phi_{\text {charge }}$ are the efficiency of the inverter and batteries for both the charging and discharging states. In the wind energy subsystem, the generation of power depends upon the speed of the wind and sometimes it is unstable and produces a variable AC. Variable AC is converted to fixed DC with the help of a rectifier, and then fixed DC is converted to fixed AC with the help of a converter to stabilize the system [36]. Batteries are used as a storage system used for storing excess power and regulating the voltage of the system and are used as a backup in case of inefficient generation of power by the system 
$[35,36]$. The output power generated by the wind subsystem is calculated by [36]

$$
Z_{P}=\frac{\left(\alpha \lambda x y^{3}\right)}{2}
$$

where $Z_{P}$ is the output power, $\alpha$ is the power coefficient, $\lambda$ is the ratio of tip speed, $y$ is the wind speed, and $x$ is the frontal area of the wind turbine.

The presented architecture in Figure 1 is the general architecture, and various studies have been conducted on this architecture. Now our goal is to optimize this architecture so that maximum power can be generated from the system. This can be done by applying optimization techniques and genetic algorithm, which are discussed as follows. The grid system is presented in Figure 2.

4.1. Optimization of Tilt Angle of the PV Array. The amount of solar energy collected is affected by the orientation and tilt of the solar panels [39]. As a result, solar panels must be installed at optimal angles in order to obtain the greatest amount of solar energy in a given area [39]. One of the methods to achieve this task is to install a sun tracker. However, sun tracker increases the complexity and costs of the system. Instead of installing sun trackers, changing the orientation angles seasonally, monthly, or yearly could be a better alternative [39]. The total solar radiation falling on a tilted surface $(\mathrm{T})$ is made up of direct/beam solar radiation $T_{\text {direct }}$, diffuse radiation $T_{\text {diffuse }}$, and ground reflected radiation $T_{\text {refer }}$ by considering isotropic reflection. Then, the average daily solar radiation on a tilted surface is given as [40]

$$
T=T_{\text {direct }} \lambda_{x}+\frac{T_{\text {diffuse }}}{2}+(1+\cos \phi)+\frac{T \psi}{2}(1-\cos \phi),
$$

where $\lambda_{x}$ is the ratio of the average beam radiation on the tilted surface to that of the horizontal surface and $\psi$ is the function of transmittance of the atmosphere. If the surface is facing the equator [40], then

$\lambda_{x}=\frac{\cos (\alpha-\beta) \cos \gamma \sin \sigma+(\pi / 180) \sigma \sin (\alpha-\beta) \sin \gamma}{\cos \alpha \cos \gamma \sin \sigma+(\pi / 180) \sigma \sin \phi \sin \gamma}$,

where $\gamma$ is the sunset hour angle, given by [40]

$$
\begin{aligned}
& \gamma=\min [\gamma=\arccos (-\tan \alpha \tan \gamma)], \\
& \gamma=\min [\arccos (-\tan (\alpha-\beta) \tan \gamma)],
\end{aligned}
$$

where min is the smallest value of the items in the brackets.

\subsection{Optimization of Microgrid Services like Storage, Batteries,} Inverter, and Wind Power. Because photovoltaic (PV) units have low maintenance costs, inverter size must be optimized to achieve system productivity. The rated power of the PV system must be optimally matched with the rated power of the inverter to achieve maximum power [41]. The optimal inverter sizing is determined by the amount of solar radiation received locally, the ambient temperature, and the inverter's performance [41]. The PV array only produces a portion of its rated power when solar radiation levels are low, and the inverter, therefore, operates at a lower efficiency [41]. The rated capacity of the inverter is lost under overloading conditions [41], which is why optimum PV array sizing is required. Not every area is suitable for wind energy systems. The amount of kinetic energy present in the wind increases with wind speed, but not all of the kinetic energy can be converted into another source of energy while passing through a wind turbine. Since the wind current begins after the rotor, a portion of its initial kinetic energy persists in the wind, causing it to continue to flow $[3,6]$. The ratio of kinetic energy (KE), when divided by the KE available in the wind, can be converted into wind turbines called power coefficient $[3,6,42]$. The power coefficient is dependent on the downstream and upstream ratio of the turbine to wind velocity. The density of the wind power is defined as the quantitative measure of the wind energy available in a particular geographical area. It is often considered the critical indicator of the potential of wind energy $[3,6,42]$. The major indicators of wind speed with optimization $[42,43]$ are defined as follows:

$$
s_{v}=x\left[1-\frac{1}{y}\right]^{(1 / y)},
$$

where $S_{\mathrm{V}}$ is the portable wind speed. The highest energycarrying speed of the wind is defined as follows [42-44]:

$$
s_{\max }=x\left(1+\frac{2}{y}\right)^{(1 / y)} \text {. }
$$

The density of the power of the wind evaluates the wind available in a particular area and is given as follows [44]:

$$
\frac{L}{A}=\frac{1}{2} \sigma v^{3} \text {. }
$$

This equation can also be written as Weibull Parameters [45] as follows:

$$
\left(\frac{L}{A}\right)_{w}=\int_{0}^{\infty} \frac{1}{2} \sigma V^{3} f v^{3} \mathrm{~d} V=\frac{1}{2} \sigma C^{3} \Gamma\left(1+\frac{3}{y}\right),
$$

where $L$ is the density of wind power represented in Watt $/ \mathrm{m}^{2}, A$ is the area swept in $\mathrm{m}^{2}, f\left(v^{3}\right)$ is the probability distribution function, and vis the speed of wind in $\mathrm{m} / \mathrm{s}$.

\section{Results' Analysis}

The software Hybrid Optimization of Multiple Energy Resources (HOMER) [46] was chosen for simulations and system design. We chose this software because it can perform essential tasks like optimization, simulation, and sensitivity analysis. After the users' data have been simulated, HOMER determines the best setup based on the lowest net present cost (NPC) [46]. Sensitivity analysis is carried out to ensure that only the best components are used in the system design. We chose the rural areas of Rajasthan, India, for system testing because the state is covered in desert, allowing ample solar energy to be harnessed. The community consumes $165.59 \mathrm{kWh}$ per day, with a peak demand 


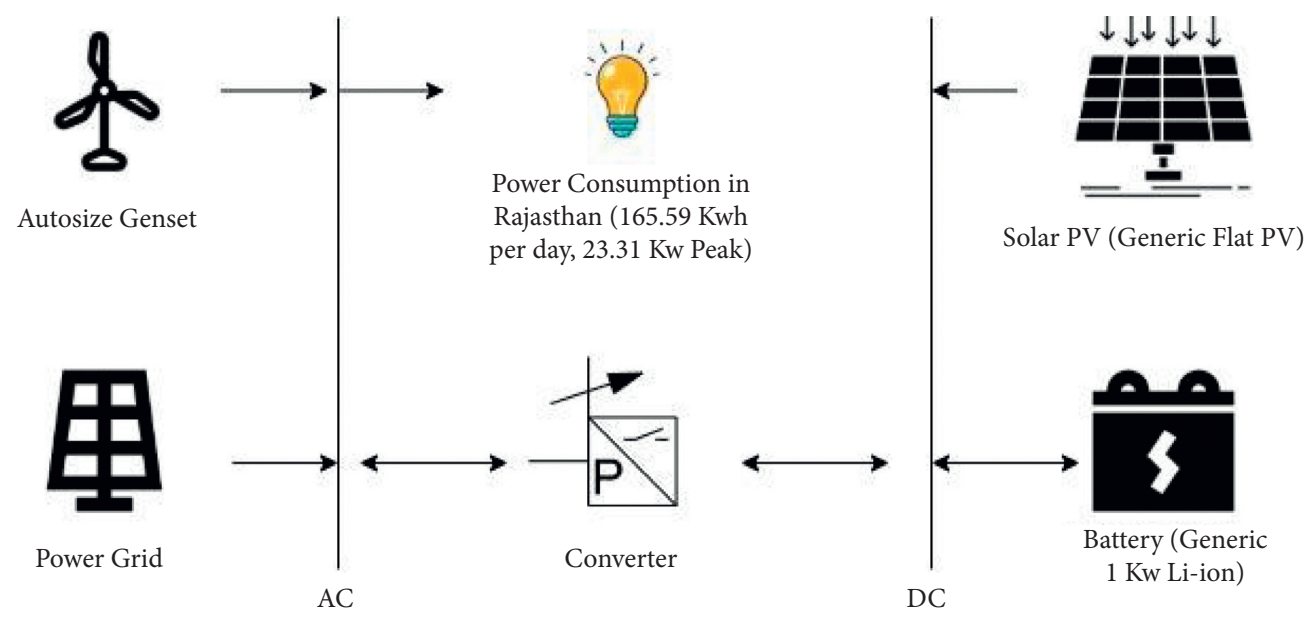

FIgURE 2: Grid system internal structure.

of $23.31 \mathrm{KW}$. The load profiles were created using public databases $[47,48]$ and a poll conducted by the Government of Rajasthan in India. The random variability from one day to the next is $10 \%$, and the variability from one-time step to the next is $20 \%$. Summer demand (May-July) was found to be moderate, and winter demand was found to be low (November-January). Electrical service can need a distribution system, whether the system is self-contained or connected to the grid [46]. A grid connection system would need an $11 \mathrm{KV} / 220 \mathrm{~V}$ step-down transformer as well as an automatic transfer switch to resolve any power distribution anomalies. The seasonal load profile generated is shown in Figure 3.

The components used for designing the system are explained in Tables $2-5$, respectively.

The purpose of using the Autosize Genset generator is that this generator automatically adjusts itself according to the load. The capacity of the generator is small so that it cannot produce capacity shortages in cases of sensitivity and in the future if the multiyear analysis is used. This generator is also capable of adjusting its fuel curve to match its size (source: http://www.homerenergy.com).

Generic $10 \mathrm{~kW}$ wind turbine is used for our study. Table 3 lists the wind turbines' various parameters, while Figure 4 depicts the power curve. The turbine's predicted lifespan was discovered to be 20 years. Although the initial investment is low, replacement costs are high. However, when compared to high-quality wind turbines during the project's lifetime, the HOMER simulation findings show that the turbine contributes to a less net present cost (NPC) due to its low capital cost [46]. The surface area criteria are based on National Renewable Energy Lab (NREL) standards [46]. According to NREL, the capacity per unit area is $3.0 \pm 1.7 \mathrm{MW} / \mathrm{km}^{2}$. Therefore, the area required for $10 \mathrm{~kW}$ wind turbine is $2500 \mathrm{~m}^{2}$. The capacity of the wind turbines can be optimized by a genetic algorithm [49] given as Algorithms 1 and2, respectively. Upon analysis of HOMER, we found that the lifetime of the overall system would be in the range of $20-30$ years, which is a good sign.

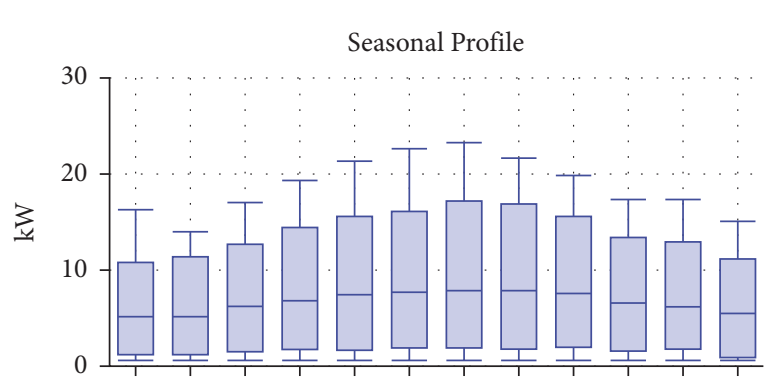

Jan Feb Mar Apr May Jun Jul Aug Sep Oct Nov Dec

FIgURE 3: Season-based load profile obtained for the suggested installation location.

TABLE 2: Generator specifications.

\begin{tabular}{lc}
\hline Type & Autosize Genset \\
\hline Size (kW) & $1.2 \mathrm{~kW}$ \\
Capital cost (INR) & $500 \mathrm{INR}$ \\
Restoration cost (INR) & $500 \mathrm{INR}$ \\
O\&M cost (per operational hour) & $0.030 \mathrm{INR}$ \\
\hline
\end{tabular}

TABLE 3: Wind turbine specifications.

\begin{tabular}{lc}
\hline Type & Generic $10 \mathrm{~kW}$ \\
\hline Hub height & 24 meters \\
Capital cost (INR) & $50000 \mathrm{INR}$ \\
Restoration cost (INR) & $50000 \mathrm{INR}$ \\
O\&M cost (per operational hour) lifetime & $500 \mathrm{INR} /$ year 20 years \\
\hline
\end{tabular}

Due to the seasonal nature of renewable energy sources, energy storage devices are necessary to ensure a constant supply of energy from renewable sources. We have considered the load following strategy [46] in developing our model. Due to the sudden increase or decrease in power supply, hybrid systems require additional reserves to tackle the challenges related to sudden increase or decrease. The operating reserve was considered as $10 \%$ of the hourly load 
TABLE 4: Storage battery specifications.

\begin{tabular}{lr}
\hline Type & Generic 1 kWh Li-ion \\
\hline Lifetime & 15 years \\
Capital cost & 550 USD \\
Restoration cost & 550 USD \\
O\&M cost (per operational hour) & 10 USD/year \\
Throughput & $3000 \mathrm{kWh}$ \\
\hline
\end{tabular}

TABLE 5: Solar PV specifications.

\begin{tabular}{lr}
\hline Type & Generic flat PV \\
\hline Derating factor & $80 \%$ \\
Capital cost & 2500 USD \\
Restoration cost & 2500 USD \\
O\&M cost (per operational hour) & 10 USD/year \\
Lifetime & 25 years \\
\hline
\end{tabular}

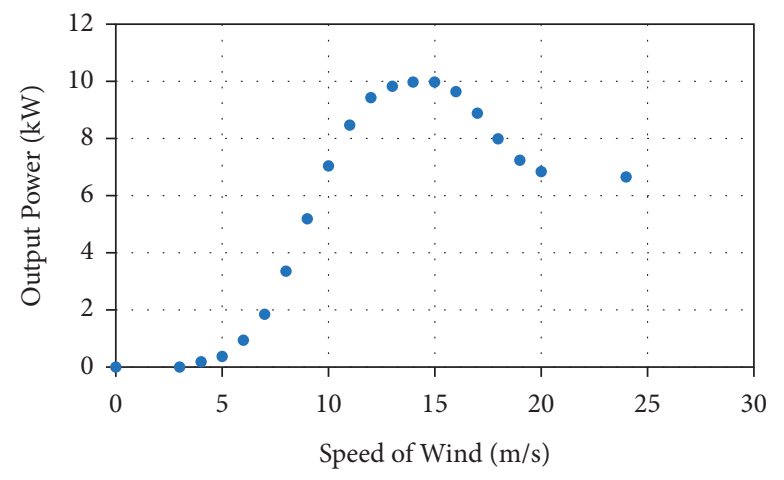

FIGURE 4: Scatter plot of the wind turbine in terms of power.

(1) Initialize $\mathrm{GA} \in[0,1]$, POS $\in \mathrm{f}(\mathrm{V}) / /$ Particle swarm optimization, $f(V)=$ Functional Decision Variables

(2) If

(3) POS optimizes $\mathrm{w}(\mathrm{f}(\mathrm{n})) \in \mathrm{NIS} / / \mathrm{NIS}=$ noninferior solutions, $w(f(n))=$ weighted single objective function

(4) Then

(5) Use Crowding Distance Method for the solutions Obtained in step 3

(6) If

(7) User submitted = true, terminate the algorithm and Solutions $=$ accepted

(8) Else

(9) Values recorded

(10) Evaluate Fitness for each individual, do Genetic Operations

(11) Return Values recorded

(12) Evaluate Fitness for each individual, do Genetic Operations

(13) Return to Step 2

Algorithm 1: Optimization of the capacity of wind turbines.

as recommended by [46] for maximizing efficiency. The specifications for the solar PV and storage devices are given in Tables 4 and 5, respectively.

5.1. Simulations and Analysis. For the evaluation of the proposed system, various configurations such as grid-only systems, renewable energy sources (RES) systems, and Grid-
RES hybrid systems are analyzed. The optimization results are recorded in Table 6 .

The HOMER findings show that the RES only setup is achievable with the available resources. This result was achieved after numerous trials, mistakes, and the removal of inefficient data in order to reduce simulation time. This system is economically feasible at $10 \%$ shortage. The monthly production of power is shown in Figure 5. In Grid- 
(1) Initialize $u=0 \mathrm{~m} / \mathrm{s}^{2} \in$ POS in decision making variables $/ / \mathrm{u}=$ initial velocity

(2) Evaluate Fitness Values, Extreme Points

(3) $\mathrm{New}_{\mathrm{u}}$ and position updated

(4) If

(5) Steps 1,2,3= True, conditions satisfied

(6) Algorithm terminated

(7) Else

(8) Go to step 2 again

Algorithm 2: For noninferior solutions.

TABLE 6: RES configuration optimization result.

\begin{tabular}{|c|c|c|c|c|c|c|c|c|c|}
\hline $\begin{array}{l}\text { PV } \\
(\mathrm{kW})\end{array}$ & $\begin{array}{l}\text { Wind } \\
\text { turbine }\end{array}$ & Battery & $\begin{array}{l}\text { Conv } \\
(\mathrm{kW})\end{array}$ & $\begin{array}{l}\text { Initial } \\
\text { capital }\end{array}$ & $\begin{array}{c}\text { Operating } \\
\text { cost } \\
\text { (USD/year) }\end{array}$ & $\begin{array}{l}\text { Net } \\
\text { NPC }\end{array}$ & $\begin{array}{c}\text { Coe } \\
(\$ / \mathrm{kWh})\end{array}$ & Renewable factor & Capacity shortage \\
\hline 26 & 10 & 100 & 25 & $\$ 63,531$ & $\$ 16,405$ & $\$ 84,413$ & 0.118 & 0.028 & 0.10 \\
\hline ------ & 11 & 120 & 25 & $\$ 77,762$ & $\$ 21,375$ & $\$ 83,201$ & 0.156 & 0.028 & 0.10 \\
\hline
\end{tabular}

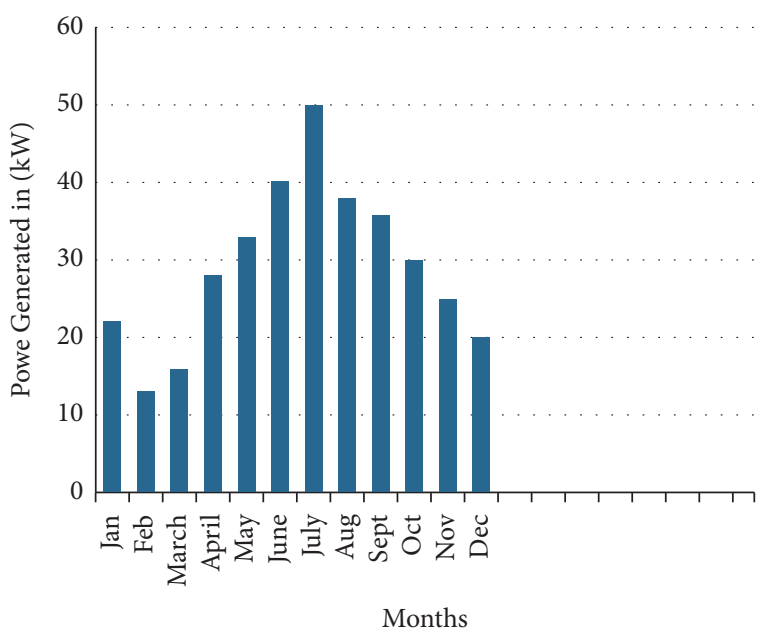

FIGURE 5: Monthly power production at $10 \%$ shortage.

RES systems, it has been found from HOMER simulations that these systems are feasible with currently available renewable resources. This type of system is also economically efficient. Upon optimization, it has been found that the system gives a net present cost (NPC) of $\$ 3,45,198$. The renewable factor for this type of configuration is $77.6 \%$. In this type of configuration, battery and inverter are not necessary as the grid network acts as a backup for the system. The monthly power production is given in Figure 6 .

5.2. Sensitivity Analysis. The control parameters of a system can be varied in sensitivity analysis to examine the effect of these parameters on the system's effectiveness [46]. This aids the designer in creating a system that is effective. A sensitivity analysis is often performed to ensure that the system is reliable. Because the aim is to protect 100 percent of the load, the energy system would be expensive. A sensitivity analysis of the capacity constraints for the system will provide the

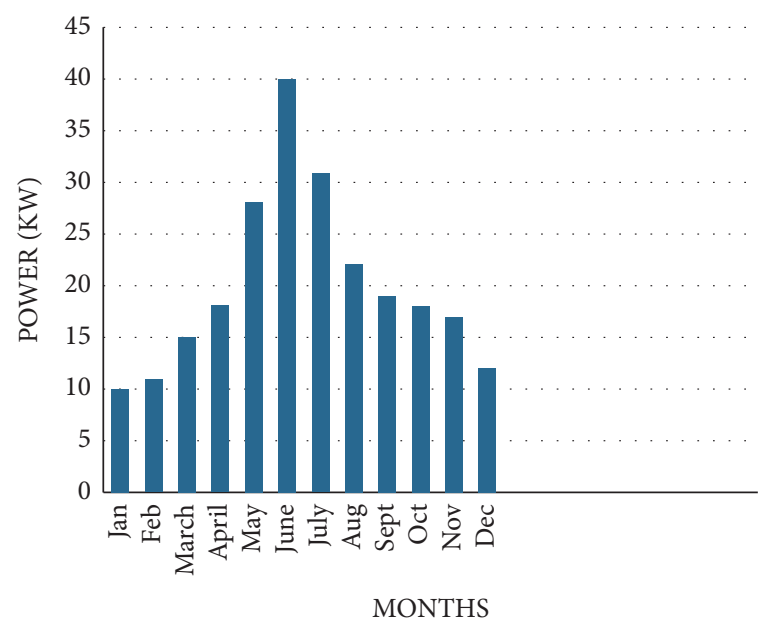

Figure 6: Monthly power production of Grid-RES system.

details about how much amount is to be paid by the customers for more effective system in terms of hours of reliability. Values from 0 to $15 \%$ with a phase of $2 \%$ were given as capacity constraints inputs. In addition, a sensitivity analysis was carried out to research the conditions under which the available findings are true for PV modules and battery prices and how much the cost of the device would differ with the variance of these prices. A sensitivity analysis was performed to evaluate all possible scenarios between these rates, where capital cost multipliers of 1.5 to 3.5 were given for the solar PV capital cost, and multipliers of 1 to 2 were given for the battery capital cost. For running the simulations, the time step was set to 40 minutes (instead of the default 60 minutes in HOMER) to effectively adjust the load and output of electricity. The maximum number of simulations per optimization was set to 25,000 . This implies that simulations would be discarded if they have not been completed until the value has been achieved. Increasing this value therefore dramatically increases the simulation time. The device design accuracy and the NPC accuracy were 


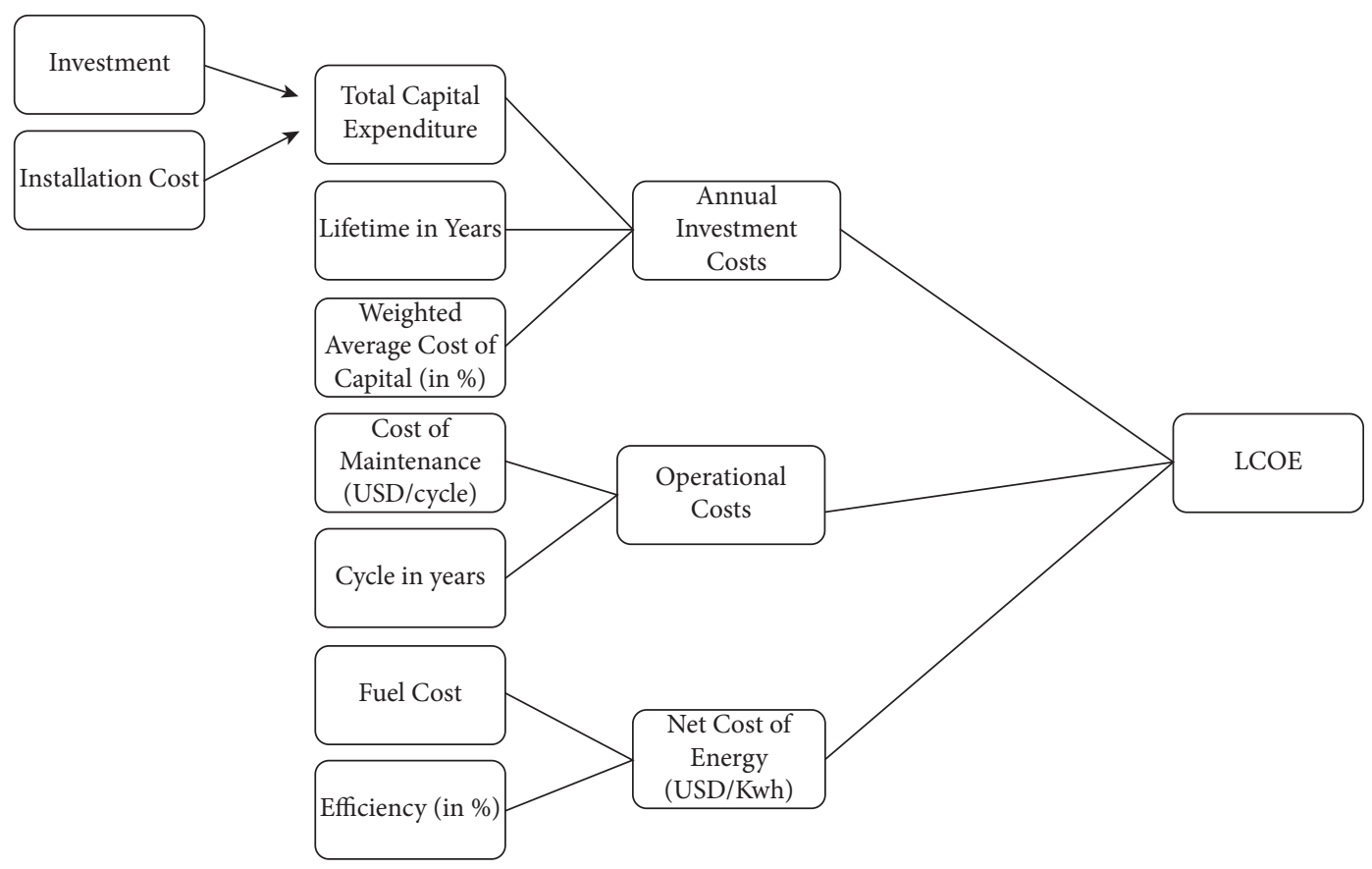

FIgURe 7: Flowchart for calculation of LCOE.

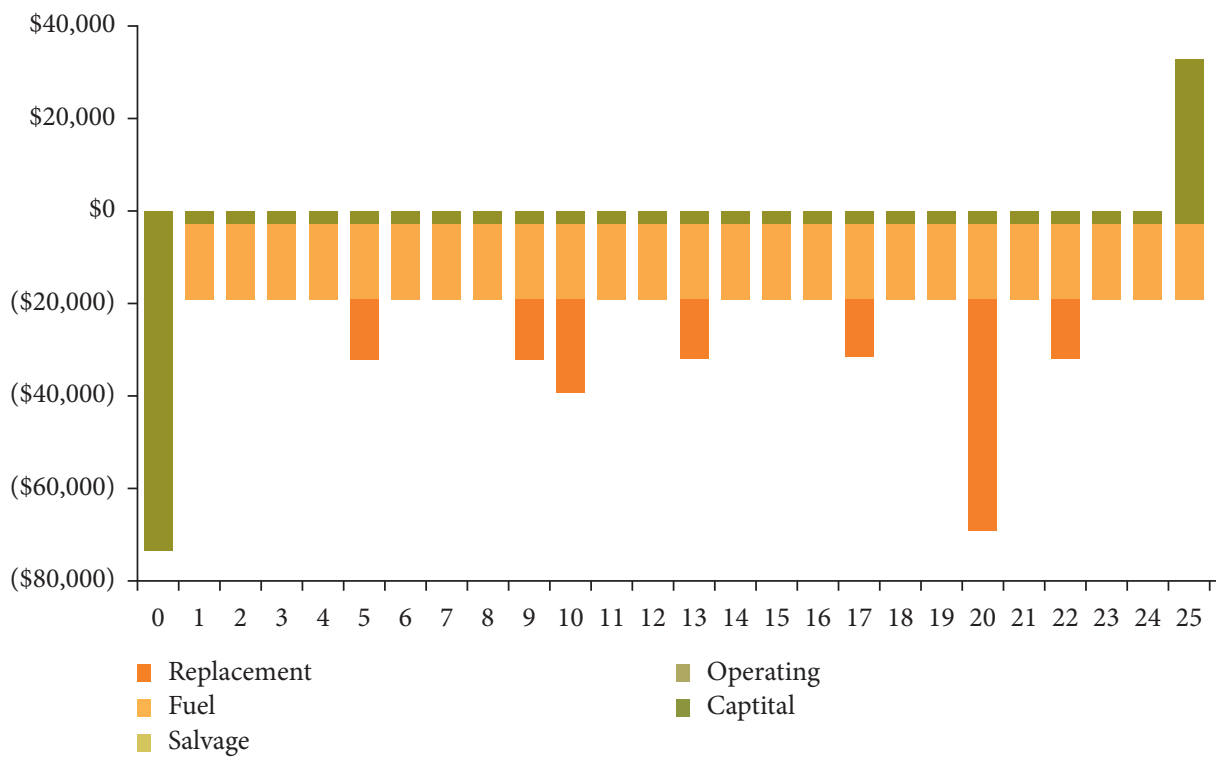

Figure 8: Cash flow diagram showing the cost efficiency of the suggested system.

TABLE 7: Cost analysis between various systems.

\begin{tabular}{lccccc}
\hline System configuration & PV array number & Number of wind generators & Battery quantity & PV converter & Cost (in USD) \\
\hline Single PV & 50 & 0 & 10 & 15 & $\$ 66,000$ \\
Single wind & 0 & 10 & 5 & 0 & $\$ 56,650$ \\
Nonoptimized & 20 & 5 & 6 & 8 & $\$$ \\
Suggested system & 15 & 6 & 6 & 6,300 \\
\hline
\end{tabular}




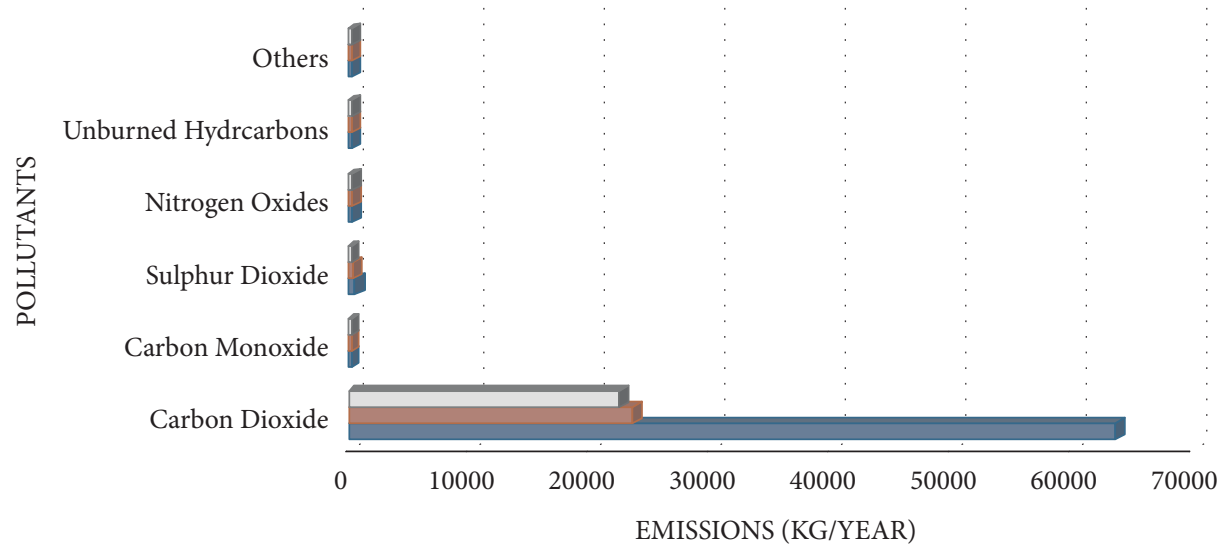

Figure 9: Comparison between greenhouse emissions of various systems. Blue bar indicates a grid-only system, orange bar indicates gridwind system, and grey bar indicates grid-wind-PV system, which is suggested.

defined by maximum simulation errors set at $1 \%$ and $2 \%$, respectively.

The efficiency of the system is shown in Figure 7, Figure 8, Table 7, and Figure 9, respectively, with a comparison between various systems in terms of cost analysis and greenhouse emissions. The flowchart for the calculation of LCOE (levelized cost of heat) [50] is given in Figure 7.

Clearly, we can see from Figure 8 that the system suggested in this paper is efficient. It can also be seen that the optimized PV system is more cost-effective than other systems. It can also be inferred from the results that most of the energy is supplied by wind.

\section{Conclusion}

Due to the growth of population and environmental pollution, the demand for efficient production of electricity has increased. Utilizing solar and wind energy for electricity production will help in resolving the challenges such as climate change and greenhouse emissions and can emerge as the best solution for resolving the energy crisis. The hybrid energy system suggested in this paper has advantages such as continuity in power supply, high efficiency, low maintenance cost, optimized utilization of the resources, and load management. The results given in this paper show that the use of hybrid PV-wind power generation units could save up to $10 \%-20 \%$ of the cost of current systems. This study encourages the use of hybrid systems in India and abroad in order to improve electricity production sustainability. Hybrid systems will provide a viable, secure power supply to rural areas while also providing a pool of funding for community grid maintenance and economic development. Ultimately, these systems will help to increase the usage of renewable energy for generating electricity globally and thereby contribute to resolving the environmental problems currently facing the world.

\section{Limitations and Future Scope of the Work}

Solar energy and wind energy undoubtedly come to people's mind when we talk about renewable energy. In an hour, the sun emits enough energy, which can cover human needs for a year.
This property makes solar energy the best form of energy to be integrated with other energy forms. However, with the current technology, we are unable to extract the full potential of the integrated systems. Some amount of energy gets wasted due to inefficient operation. According to recent reports [51], it has been shown that the PV panels have a median degradation rate of $0.5 \%$ per year. It may be high in hot climate areas and rooftop systems. The degradation rate of $0.5 \%$ shows that the energy production from solar PV will decrease at the rate of $0.5 \%$ per year. This will make the system inefficient over time. Furthermore, the unpredictability and intermittency of solar energy make the solar PV panel less reliable. Solar panels require additional inverters to convert $\mathrm{DC}$ to $\mathrm{AC}$ energy in order to be used on the power network, which makes the system complex and increases the installation time and circuit development costs. For a continuous supply of electricity on grid connections, $\mathrm{PV}$ panels also require storage batteries along with inverters, which also increases the investment costs. Moreover, the installation of solar PV panels usually requires a large area of land for a period of more than 20 years. Also, solar PV is fragile and can be damaged easily, so insurance costs also increase the overall costs of the systems. Our future work will be based on resolving these challenges and the development of microenergy grids with micro-PV cells, which would require less complexity and installation area. This system will be further integrated with blockchain technology to increase the efficiency of the system.

\section{Data Availability}

The data used to support the findings of this study are available from the corresponding author upon request.

\section{Conflicts of Interest}

The authors declare that they have no conflicts of interest.

\section{Acknowledgments}

This research was supported by the Taif University Research Supporting Project no. TURSP-2020/311, Taif University, Taif, Saudi Arabia. 


\section{References}

[1] S. Sanajaoba, "Optimal sizing of off-grid hybrid energy system based on minimum cost of energy and reliability criteria using firefly algorithm," Solar Energy, vol. 188, pp. 655-666, 2019.

[2] F. Husni, Y. Tan, and J. Yan, "Power and Methanol Production from Biomass Combined with Solar and Wind Energy: Analysis and Comparison," Energy Procedia, vol. 145, pp. 576-581, 2018.

[3] C. Mata Yandiola, Feasibility Analysis of the Use of Hybrid Solar PV-Wind Power Systems for Grid Integrated Mini-Grids in India, Dissertation, KTH, School of Industrial Engineering and Management (ITM). Selco Foundation, Stockholm, Sweden, 2017.

[4] Y. Kassem, H. Çamur, and R. A. F. Aateg, "Exploring solar and wind energy as a power generation source for solving the electricity crisis in Libya," Energies, vol. 13, no. 14, p. 370, 2020.

[5] S. Al-Mimar, Integration of Solar and Wind Power at Lillgrundwind farm Wind Turbine Shadow Effect on Solar Farm atLillgrund Wind Farm, Halmstad University, Halmstad, Sweden, 2015, http://www.diva-portal.org/smash/record.jsf? pid $=$ diva2\%3A817812\&dswid $=9794$.

[6] F. Ueckerdt, Integrating Variable Electricity Supply from Wind and Solar PV into Power Systems, Technische Universität Berlin, Berlin, Germany, Berlin, 2014.

[7] G. Notton, "Hybrid wind-photovoltaic energy systems," in Stand-Alone and Hybrid Wind Energy SystemsWoodhead Publishing, Sawston, UK, 2010.

[8] T. Mitani, M. Aziz, T. Oda, A. Uetsuji, Y. Watanabe, and T. Kashiwagi, "Annual assessment of large-scale introduction of renewable energy: modeling of unit commitment schedule for thermal power generators and pumped storages," Energies, vol. 10, p. 738, 2017.

[9] F. Tang, H. Zhou, Q. Wu, H. Qin, J. Jia, and K. Guo, "A Tabu search algorithm for the power system islanding problem," Energies, vol. 8, no. 10, pp. 11315-11341, 2015.

[10] F. Capitanescu and L. Wehenkel, "Experiments with the interior-point method for solving large scale Optimal Power Flow problems," Electric Power Systems Research, vol. 95, pp. 276-283, 2013.

[11] L. Canale, A. R. Di Fazio, M. Russo, A. Frattolillo, and M. Dell'Isola, "An overview on functional integration of hybrid renewable energy systems in multi-energy buildings," Energies, vol. 14, no. 4, p. 1078, 2021.

[12] G. J. Osório, M. Shafie-khah, J. M. Lujano-Rojas, and J. P. S. Catalão, "Scheduling model for renewable energy sources integration in an insular power system," Energies, vol. 11, p. 144, 2018.

[13] L. M. S. de Siqueira and W. Peng, "Control strategy to smooth wind power output using battery energy storage system: a review," Journal of Energy Storage, vol. 35, Article ID 102252, 2021.

[14] I. Akhtar and S. kirmani, "Design and implementation of model predictive control for microgrid energy system with power quality improvement features," International Journal of Electronics, vol. 108, no. 12, pp. 1977-1998, 2021.

[15] T. Mai, A. Lopez, M. Mowers, and E. Lantz, "Interactions of wind energy project siting, wind resource potential, and the evolution of the U.S. power system," Energy, vol. 223, Article ID 119998, 2021.

[16] B. Setiawan, E. S. Putra, I. Siradjuddin, and M. Junus, "Optimisation solar and wind hybrid energy for model catamaran ship,” IOP Conference Series: materials Science and Engineering, vol. 1073, no. 1, Article ID 012044, 2021.

[17] L. Sun, Y. Jin, J. Shen, and F. You, "Sustainable residential micro-cogeneration system based on a fuel cell using dynamic programming-based economic day- ahead scheduling," ACS Sustainable Chemistry \& Engineering, vol. 9, no. 8, pp. 3258-3266, 2021.

[18] A. Awasthi, A. K. Shukla, M. M. S.R. et al., "Review on sun tracking technology in solar PV system," Energy Reports, vol. 6, pp. 392-405, 2020.

[19] A. Ghafoor and A. Munir, "Design and economics analysis of an off-grid PV system for household electrification," Renewable and Sustainable Energy Reviews, vol. 42, pp. 496-502, 2015.

[20] M. Al-Addous, Z. Dalala, C. B. Class, F. Alawneh, and H. Al-Taani, "Performance analysis of off-grid PV systems in the Jordan Valley," Renewable Energy, vol. 113, pp. 930-941, 2017.

[21] Ghenai, Chouki, and M. Bettayeb, "Grid-tied solar PV/fuel cell hybrid power system for university building," Energy Procedia, vol. 159, pp. 96-103, 2019.

[22] M. A. V. Rad, R. Ghasempour, P. Rahdan, S. Mousavi, and M. Arastounia, "Techno-economic analysis of a hybrid power system based on the cost-effective hydrogen production method for rural electrification, a case study in Iran," Energy, vol. 190, Article ID 116421, 2020.

[23] L. Qi, P. Zheng, X. Wu, W. Duan, L. Li, and Z. Zhang, "A hybrid wind-photovoltaic power generation system based on the foldable umbrella mechanism for applications on highways," Solar Energy, vol. 208, pp. 368-378, 2020.

[24] N. Bizon and P. Thounthong, "Energy efficiency and fuel economy of a fuel cell/renewable energy sources hybrid power system with the load-following control of the fueling regulators," Mathematics, vol. 8, no. 2, p. 151, 2020.

[25] T. Salameh, M. A. Abdelkareem, A. G. Olabi, E. T. Sayed, M. Al-Chaderchi, and H. Rezk, "Integrated standalone hybrid solar PV, fuel cell and diesel generator power system for battery or supercapacitor storage systems in Khorfakkan, United Arab Emirates," International Journal of Hydrogen Energy, vol. 46, no. 8, pp. 6014-6027, 2021.

[26] V. A. Ani, "Development of an intelligent power management system for solar PV-Wind-Battery-Fuel-Cell integrated system," Frontiers in Energy Research, vol. 9, p. 31, 2021.

[27] Y. Noorollahi, A. Khatibi, and S. Eslami, "Replacing natural gas with solar and wind energy to supply the thermal demand of buildings in Iran: a simulation approach," Sustainable Energy Technologies and Assessments, vol. 44, Article ID 101047, 2021.

[28] P. D. Santos, A. C. Zambroni de Souza, B. D. Bonatto, T. P. Mendes, J. A. S. Neto, and A. C. B. Botan, "Analysis of solar and wind energy installations at electric vehicle charging stations in a region in Brazil and their impact on pricing using an optimized sale price model," International Journal of Energy Research, vol. 45, no. 5, pp. 6745-6764, 2021.

[29] O. Siddiqui and I. Dincer, "Optimization of a new renewable energy system for producing electricity, hydrogen and ammonia," Sustainable Energy Technologies and Assessments, vol. 44, Article ID 101023, 2021.

[30] Z. Qadir, S. I. Khan, E. Khalaji, H. S. Munawar, F. Al-Turjman, and M. P. Mahmud, K. Le, Predicting the energy output of hybrid PV-wind renewable energy system using feature selection technique for smart grids," Energy Reports, vol. 7, pp. 8465-8475, 2021. 
[31] M. Ian, E. Gençer, and F. M. O'Sullivan, “A general model for estimating emissions from integrated power generation and energy storage. Case study: integration of solar photovoltaic power and wind power with batteries," Processes, vol. 6, no. 12, p. 267, 2018.

[32] S. M. Lawan and W. A. W. Z. Abidin, A Review of Hybrid Renewable Energy Systems Based on Wind and Solar Energy: Modeling, Design and Optimization, Wind Solar Hybrid Renewable Energy System, IntechOpen Limited, London, UK, 2020.

[33] J. Kaustubh, T. Shelar, S. Sanap, and N. Sangit, "Dual power generation solar plus windmill generator," New Arch-International Journal of Contemporary Architecture, vol. 8, no. 2, pp. 1002-1006, 2021.

[34] J. Godson, M. Karthick, T. Muthukrishnan, and M. S. Sivagamasundari, "Solar PV-Wind hybrid power generation System," International Journal of Advanced Research in Electrical, Electronics and Instrumentation Engineering, vol. 2, no. 11, pp. 5350-5354, 2013.

[35] J. Godson, M. Karthick, T. Muthukrishnan, and M. S. Sivagamasundari, "Solar PV-Wind hybrid power generation system," International Journal of Advanced Research in Electrical, Electronics and Instrumentation Engineering, vol. 2, no. 11, pp. 5350-5354, 2013.

[36] M. Srikanth, T. V. Muni, M. V. Vardhan, and D. Somesh, "Design and simulation of PV-wind hybrid energy system," J Adv Res Dyn Control Syst, vol. 10, pp. 999-1005, 2018.

[37] L. Zhang, R. Belfkira, and G. Barakat, "Wind/PV/diesel energy system: modeling and sizing optimization," in Proceedings of the 2011-14th European Conference on Power Electronics Application (EPE 2011), pp. 1-10, Birmingham, UK, 2011.

[38] W. M. Hamanah, M. A. Abido, and L. M. Alhems, "Optimum sizing of hybrid pv, wind, battery and diesel system using lightning search algorithm," Arabian Journal for Science and Engineering, vol. 45, no. 3, pp. 1871-1883, 2020.

[39] T. Khatib, A. Mohamed, and K. Sopian, "Optimization of a $\mathrm{PV} /$ wind micro-grid for rural housing electrification using a hybrid iterative/genetic algorithm: case study of Kuala Terengganu, Malaysia," Energy and Buildings, vol. 47, pp. 321-331, 2012.

[40] A. Kumar, N. S. Thakur, R. Makade, and M. K. Shivhare, "Optimization of tilt angle for photovoltaic array," International Journal of Engineering Science and Technology, vol. 3, no. 4, pp. 3153-3161, 2011.

[41] T. Khatib, A. Mohamed, and K. Sopian, "A review of photovoltaic systems size optimization techniques," Renewable and Sustainable Energy Reviews, vol. 22, pp. 454-465, 2013.

[42] F. Fazelpour, E. Markarian, and N. Soltani, "Wind energy potential and economic assessment of four locations in Sistan and Balouchestan province in Iran," Renewable Energy, vol. 109, pp. 646-667, 2017.

[43] S. H. Pishgar-Komleh, A. Keyhani, and P. Sefeedpari, "Wind speed and power density analysis based on Weibull and Rayleigh distributions (a case study: firouzkooh county of Iran)," Renewable and Sustainable Energy Reviews, vol. 42, pp. 313-322, 2015.

[44] K. Mohammadi, O. Alavi, and J. G. Mcgowan, "Use of Birnbaum-Saunders distribution for estimating wind speed and wind power probability distributions: a review," Energy Conversion and Management, vol. 143, pp. 109-122, 2017.

[45] A. Keyhani, M. Ghasemi-Varnamkhasti, M. Khanali, and R. Abbaszadeh, "An assessment of wind energy potential as a power generation source in the capital of Iran, Tehran," Energy, vol. 35, no. 1, pp. 188-201, 2010.
[46] S. Podder, R. S. Khan, and S. M. A. Alam Mohon, "The technical and economic study of solar-wind hybrid energy system in coastal area of Chittagong, Bangladesh," Journal of Renewable Energy, 2015.

[47] P. W. Stackhouse and C. H. Whitlock, "The National Aeronautics and Space Administration," 2016, https:// cleanenergysolutions.org/resources/surface-meteorol ogy-solar-energy-website.

[48] Finding Data to Run HOMER, 2022, https://www.homerene rgy.com/products/pro/docs/latest/finding_data_to_run_hom er.html.

[49] T. Wei Sun and W. Sun, "Optimization of wind-PV hybrid power system based on interactive multi-objective optimization algorithm," in Proceedings of the 2012 International Conference on Measurement, Information and Control, pp. 853-856, Harbin, 2012.

[50] O. Gudmundsson, J. E. Thorsen, and L. Zhang, "Cost analysis of district heating compared to its competing technologies," WIT Transactions on Ecology and the Environment, vol. 176, pp. 3-13, 2013.

[51] B. Mow, STAT FAQs Part 2: Lifetime of PV Panels, 2022, https://www.nrel.gov/state-local-tribal/blog/posts/stat-faqspart2-lifetime-of-pv-panels.html. 